\section{Effect of Irrigation Frequency on Subsurface Drip Irrigated Vegetables}

\author{
Blaine R. Hanson, ${ }^{1}$ \\ Donald M. May, and \\ Larry J. Schwankl
}

\begin{abstract}
Summary. The effect on crop yield of drip-irrigation frequencies of two irrigations per day $(2 / d)$, one irrigation per day $(1 / d)$, two irrigations per week ( 2 /week), and one irrigation per week ( 1 /week) was investigated for lettuce (Lactuca sativa), pepper (Capsicum annuиm), and onion (Allium cepa) grown on sandy loam and processing tomato (Lycopersicon esculentum) grown on silt loam during experiments conducted during 1994 to 1997 . All treatments of a particular crop received the same amount of irrigation water per week. Results showed that the 1 /week frequency should be avoided for the shallow rooted crops in sandy soil. Irrigation frequency had little effect on yield of tomato, a relatively deep-rooted crop. These results suggest that drip irrigation frequencies of $1 / \mathrm{d}$ or $2 /$ week are appropriate in medium to fine texture soils for the soil and climate of the project site. There was no yield benefit of multiple irrigations per day.
\end{abstract}

$\mathrm{D}$ rip irrigation of row crops is increasing in California because it offers the advantage of precisely applying both water and fertilizer at a high efficiency, thus creating a potential for larger yields and reduced water and fertilizer applications. The desired frequency of drip irrigation depends on factors such as soil texture, rooting pattern about the drip line, wetting around the drip line, evapotranspiration (ET) rate, rainfall, and crop

Department of Land, Air and Water Resources, University of California, Davis, CA 95616.

${ }^{1}$ To whom reprint requests should be addressed; e-mail address: brhanson@ucdavis.edu. type. Frequent irrigations maintain relatively constant soil moisture content with time, an objective of drip irrigation. However, very frequent irrigation such as multiple irrigations per day can result in much time spent filling pipelines and laterals, and the frequent drainage of pipelines after cutoff of irrigation water can create nonuniform water applications and increase the potential for phytophthora (Phytophthora parasitica) caused by excessive soil moisture content along the lower end of the field, a problem experienced by some growers. Infrequent drip irrigations may cause water stress between irrigations in some crops and soil textures because of a limited amount of stored soil moisture due to both the wetting and root patterns around the drip line. Infrequent irrigations on coarse-textured soils also could result in substantial percolation below the root zone during irrigation because of their limited soil moisture storage capacity, which reflects the wetting pattern around the drip line. From a grower's perspective, however, less frequent irrigations reduce labor and management requirements although automation could reduce labor even under very high frequency irrigation.

A number of projects on drip irrigation frequency have been conducted. Drip irrigation frequencies of 7 to 8 times per day and about every $3 \mathrm{~d}$ during periods of maximum ET had no statistically significant effect on tomato yield in clay loam (Hutmacher et al., 1985). On loam soil, greater cantaloupe (Cucumis melo) yields occurred for weekly irrigations compared to daily irrigations, higher onion yield for daily irrigations compared with weekly irrigations, and irrigation frequency had little effect on carrot (Daucus carota) yield (Bucks et al., 1980). A trend of increasing tomato yield with decreasing irrigation interval was found on a loam for irrigation intervals of 1,2 and $5 \mathrm{~d}$ (Freeman et al., 1976). Little irrigation frequency effect was found on cabbage (Brassica oleracea Capitata Group) yield for intervals of 3, 6 and $12 \mathrm{~d}$ on clay loam (Bucks et al., 1974). The effect of drip irrigation frequencies of $1,3,5$ and $7 \mathrm{~d}$ on corn (Zea mays) yield grown in a silt loam was not critical (Caldwell et al., 1994). Larger cucumber (Cucumis sativus) yield in a greenhouse and larger tomato yield in a field occurred for daily irrigations compared with every $3 \mathrm{~d}$ (ElGindy and El-Araby, 1996). Higher potato (Solanum tuberosum) yield was found for more frequent drip irrigation, but no consistent trend was found for lettuce (Sammis, 1980). Onion yield was unaffected by drip irrigation frequencies of $\mathrm{l}$ and $3 \mathrm{~d}$ on clay loam (Ellis et al., 1986).

Irrigation frequencies used in these studies, which ranged from multiple times per day to more than 1 week between irrigations, showed no consistent trend between drip irrigation frequency and crop yield for the site-specific conditions. Little information is available on the effect of drip irrigation frequency of row crops for the conditions along the west side of the Central Valley of California. This study investigated the effect of irrigation frequency on drip irrigated vegetable crops grown along the west side of the valley.

\section{Materials and methods}

EXPERIMENTAL SITE AND TREATMENTS. Crisphead lettuce, processing onion, pepper, and processing tomato were grown from 1994 to 1995 at the University of California Westside Research and Extension Center, Five Points, Calif. on the west side of the San Joaquin Valley. Treatments consisted of drip irrigation frequencies of $2 / \mathrm{d}, 1 / \mathrm{d}$, $2 /$ week, and $1 /$ week. This range of frequencies was based on grower practices and recommendations by researchers. Each treatment was replicated six times in a randomized block experimental design. High flow drip tape [0.45 gal $/ \mathrm{min}$ per $100 \mathrm{ft}\left(298 \mathrm{~L} \cdot \mathrm{h}^{-1}\right.$ per $100 \mathrm{~m})$ ] with emitters spaced every 12 inches $(30.5 \mathrm{~cm})$ was installed 8 to 9 inches $(20.3 \mathrm{~cm}$ to $22.9 \mathrm{~cm})$ below the ground surface for all treatments. Tomatoes were grown on silt loam; the other crops were grown on sandy loam.

Head lettuce (fall and spring), processing onion, and pepper were grown on 40 -inch $(101.6 \mathrm{~cm})$ beds with four beds per plot. Each plot was $44 \mathrm{ft}$ ( 13.3 $\mathrm{m})$ long. Before bed listing, $300 \mathrm{lb} / \mathrm{acre}$ $\left(336.8 \mathrm{~kg} \cdot \mathrm{ha}^{-1}\right)$ of $11 \mathrm{~N}-22.9 \mathrm{P}-0 \mathrm{~K}$ fertilizer was broadcast over the plots. Sprinkler irrigation was used for stand establishment. During the irrigation season, urea ammonium nitrate (UAN-32) was injected weekly at a rate of $20 \mathrm{lb} /$ acre $\left(22.4 \mathrm{~kg} \cdot \mathrm{ha}^{-1}\right)$ of $\mathrm{N}$ per week with a positive displacement injection pump. For fall and spring lettuce, $120 \mathrm{lb} / \mathrm{acre}$ $\left(134.7 \mathrm{~kg} \mathrm{ha}^{-1}\right.$ ) of $\mathrm{N}$ were applied through the drip system. For both onions and peppers, $220 \mathrm{lb} /$ acre $(247.0$ $\mathrm{kg} \cdot \mathrm{ha}^{-1}$ ) of N were applied through the drip system. Lettuce and processing 
onions were planted by commercial growers using the variety being planted when the experimental plots were planted. The lettuce and onion variety names were not obtained. The pepper variety was 'Jupiter.'

Lettuce, onion, and pepper experiments were hand harvested with two harvested beds per plot. The onions were classified as marketable and nonmarketable. Marketable onions were those that would not pass through a 1.5-inch $(3.8-\mathrm{cm})$ digger chain. The peppers were classified by the commercial grades of extra large [50 to 60 peppers per $30-\mathrm{lb}$ (13.6-kg) box], large (60 to 70 peppers/box), medium (70 to 85 peppers/box), and culls (nonmarketable peppers).

'Heinz 8892' processing tomato was planted on 66 inches $(167.6 \mathrm{~cm})$ beds with three beds per plot. Each plot was $131 \mathrm{ft}(39.9 \mathrm{~m})$ long. A preplant application of $110 \mathrm{lb} /$ acre (123.5 $\mathrm{kg} \cdot \mathrm{ha}^{-1}$ ) of $11 \mathrm{~N}-22.8 \mathrm{P}-0 \mathrm{~K}$ fertilizer was applied followed by a 2 -inch (5.1$\mathrm{cm})$ sprinkler irrigation. During the drip irrigation, $180 \mathrm{lb} /$ acre $\left(202.1 \mathrm{~kg} \cdot \mathrm{ha}^{-1}\right)$ of $\mathrm{N}$ was applied through the irrigation system at a weekly rate of $20 \mathrm{lb} /$ acre. The middle bed of each plot was machine harvested to obtain the red fruit yield. A subsample of unsorted fruit from each plot was used to determine percent red, green and nonmarketable fruit, soluble solids and color.

In addition, a second project was conducted at the University of California, Davis on the effect of both drip irrigation frequency and depth of drip tape on 'BOS3315' processing tomato yields in 1996 and 1997. Tape depths were 6 inches $(15.2 \mathrm{~cm}), 12$ inches $(30.5 \mathrm{~cm})$, and 18 inches $(45.7 \mathrm{~cm})$, while irrigation frequencies were $1 / d$, 2 /week, and 1 /week. Soil type was a silt loam. The tape discharge rate was 0.37 $\mathrm{gal} / \mathrm{min}$ per $100 \mathrm{ft}\left(248 \mathrm{~L} \cdot \mathrm{h}^{-1}\right.$ per 100 $\mathrm{m})$, and the emitter spacing was 12 inches. The treatments were replicated four times with three beds per plot. Data collected from $20 \mathrm{ft}(6.1 \mathrm{~m})$ long handharvested plots were red fruit yield, solids, and color.

Yield data were statistically analyzed using analysis of variance (ANOVA) techniques for randomized block designs. Duncan's multiple range test was used to identify treatments that were statistically different.

Applied water. The same amount of water was applied weekly to all treatments of each crop. Amounts applied equaled the calculated crop evapotranspiration determined by multiplying reference grass evapotranspiration by weekly measurements of canopy coverage expressed as the fraction of the bed area shaded by the canopy at midday. Climatic data from the California Irrigation Management Information System (CIMIS) weather station located at the University of California Westside Research and Extension Center and at the University of California, Davis were used for the reference crop evapotranspiration. This approach, which assumes a one-to-one relationship between percent canopy coverage and basal crop coefficient, was used because of a lack of reliable crop coefficients for these crops in this area at the time of these experiments. Once the canopy coverage reached between 70 to $80 \%$, a crop coefficient of one was used. Justification for this approach is found in Hartz (1993) and Grattan et al. (1998). Effective rainfall was negligible during the irrigation seasons except for the spring lettuce.

SOIL MOISTURE MEASUREMENT. Because of uncertainty in crop coefficients, soil moisture content was measured with a neutron moisture meter in selected plots to insure that sufficient water was applied. The access tube was located about 6 inches from the drip line. In addition, for both the onion and west side tomato crops, a grid of electrical resistance gypsum blocks was installed in one plot of each treatment to measure wetting patterns around the drip line. The purpose of these measurements was to determine the effect of irrigation frequency on wetting around the drip line. This grid was developed by installing blocks at different depths for various distances from the drip tape. While gypsum blocks may not be very reliable for irrigation scheduling, they performed satisfactorily in describing the extent of wetting about the drip tape at a relatively low cost. Block readings were converted to volumetric soil moisture content using a calibration curve.

\section{Results and discussion}

Average Yields. Actual plotyields were used for the ANOVA to determine any statistical differences between treatments for each crop. However, because of a lack of information on some of the harvested areas for several crops, the average yields were normalized and expressed as a relative average yield for discussion purposes. For a given crop, the relative yield is the ratio of the average yield of a given irrigation frequency to the yield of the irrigation frequency with the maximum yield. This approach was found to better show trends in the results compared to using actual average yield values. The relative average yields are in Table 1 .

Onion. Onion yield was separated into marketable and culls [diameter less than 1.25 inches $(3.2 \mathrm{~cm})$ ]. About 30 inches $(76.2 \mathrm{~cm})$ of water was applied to each treatment. The maximum marketable yield occurred for the $1 / \mathrm{d}$ treatment, while the minimum yield occurred for the 1 / week treatment (Table $1)$. The 1 /week yield was statistically

Table 1. Average relative yields by crop and drip irrigation frequency for irrigation frequencies of two irrigations per day, one irrigation per day, two irrigations per week, and one irrigation per week. Relative yields were calculated as the ratio of the average crop yield of a given irrigation frequency to the yield of the irrigation frequency with the maximum yield for that crop.

\begin{tabular}{lcccccc}
\hline & \multicolumn{5}{c}{ Relative yield } \\
\cline { 2 - 7 } $\begin{array}{l}\text { Irrigation } \\
\text { frequency }\end{array}$ & Onion $^{\mathbf{z}}$ & $\begin{array}{c}\text { Fall } \\
\text { lettuce }^{\mathbf{z}}\end{array}$ & $\begin{array}{c}\text { Spring } \\
\text { lettuce }^{\mathbf{z}}\end{array}$ & Pepper $^{\mathbf{z}}$ & $\begin{array}{c}\text { 1st tomato } \\
\text { crop }^{\mathbf{z}}\end{array}$ & $\begin{array}{c}\text { 2nd tomato } \\
\text { crop }^{\mathbf{z}}\end{array}$ \\
\hline 2 irrigations/d & $0.94 \mathrm{a}$ & $1.00 \mathrm{a}$ & $0.90 \mathrm{a}$ & $0.88 \mathrm{ab}$ & $0.87 \mathrm{~b}$ & $0.95 \mathrm{a}$ \\
l irrigation/d & $1.00 \mathrm{a}$ & $1.00 \mathrm{a}$ & $1.00 \mathrm{a}$ & $1.00 \mathrm{a}$ & $1.00 \mathrm{a}$ & $0.98 \mathrm{a}$ \\
2 irrigations/week & $0.91 \mathrm{a}$ & $0.91 \mathrm{a}$ & $0.91 \mathrm{a}$ & $0.91 \mathrm{a}$ & $0.90 \mathrm{ab}$ & $1.00 \mathrm{a}$ \\
l irrigation/week & $0.77 \mathrm{~b}$ & $0.77 \mathrm{a}$ & $0.91 \mathrm{a}$ & $0.86 \mathrm{~b}$ & $0.88 \mathrm{ab}$ & $0.92 \mathrm{a}$ \\
CV (\%) & 9.62 & 16.13 & 12.78 & 10.38 & 10.20 & 9.16 \\
\hline
\end{tabular}

Treatments with the same letter are statistically similar at a level of significance of 0.05 . 
Table 2. Average relative yields of the pepper grades. Relative yields were calculated as the ratio of the average crop yield of a given irrigation frequency to the yield of the irrigation frequency with the maximum yield for that crop. Grade ratings are extra large [50 to 60 peppers $/ 30-1 b(13.6-\mathrm{kg})$ box], large (60 to 70 peppers/box), medium ( 70 to 85 peppers/box), and culls ( $>85$ peppers/ box).

\begin{tabular}{lcccc}
\hline Irrigation & \multicolumn{4}{c}{ Relative yields of pepper grades } \\
\cline { 2 - 5 } frequency & Extra large $^{\mathbf{z}}$ & Large $^{\mathbf{z}}$ & Medium $^{\mathbf{z}}$ & Culls $^{\mathbf{z}}$ \\
\hline 2 irrigations/d & $0.66 \mathrm{a}$ & $0.88 \mathrm{a}$ & $0.95 \mathrm{ab}$ & $0.81 \mathrm{~b}$ \\
1 irrigation/d & $1.00 \mathrm{a}$ & $1.00 \mathrm{a}$ & $1.00 \mathrm{a}$ & $0.85 \mathrm{ab}$ \\
2 irrigations/week & $0.79 \mathrm{a}$ & $0.94 \mathrm{a}$ & $0.92 \mathrm{ab}$ & $1.00 \mathrm{a}$ \\
1 irrigation/week & $0.80 \mathrm{a}$ & $0.94 \mathrm{a}$ & $0.83 \mathrm{~b}$ & $0.88 \mathrm{ab}$ \\
$\mathrm{cv}(\%)$ & 35.03 & 21.61 & 11.17 & 14.58 \\
\hline
\end{tabular}

${ }^{\mathrm{z}}$ Treatments with the same letter are statistically similar at a level of significance of 0.05 .

different from the other treatments at a level of significance of $5 \%$. Differences between the other three treatments were not statistically different. Maximum cull yield occurred for the $1 /$ week treatment while the minimum yield occurred for the $1 / \mathrm{d}$ (data not shown). None of the cull yields were statistically different. Irrigation frequency did not significantly affect soluble solids of the onions, which ranged from $22.7 \%$ (2/week) to $23.2 \%$ (1/week).

Letruce. Only three of the six replicates of the fall lettuce trial were harvestable. Cotton defoliant sprayed on nearby cotton (Gossypium hirsutum) plots drifted onto the lettuce and damaged the plants in three of the blocks. A spring crop followed the fall lettuce; however, the wet winter of that year may have obscured any potential irrigation frequency effects. Applied water for the spring lettuce was 4.5 inches (11.4 $\mathrm{cm})$. Applied water for the fall crop was unavailable.

For both crops, differences in relative average lettuce yields were not statistically significant. However, the low- est yield of the fall lettuce occurred for the $1 /$ week treatment and the highest yield for the $2 / \mathrm{d}$ and $1 / \mathrm{d}$ treatments. Lack of statistical significance may have been due to the reduced number of replications. For the spring crop, the highest yield occurred for the $1 / d$ treatment. Yields were similar for the other irrigation frequencies.

Pepper. Applied water was 15.6 inches $(39.6 \mathrm{~cm})$ for each treatment. The largest total yield occurred for the 1/d treatment, while the smallest yield occurred for the $1 /$ week treatment (Table 1 ). Yield of the $2 / \mathrm{d}$ treatment was slightly larger than the $1 /$ week treatment. The $1 / \mathrm{d}$ yield was significantly different from the $1 /$ week yield, but not from the yields of the other treatments.

Table 2 summarizes the relative average cumulative pepper yields for harvests of 20 July, 27 July, and 22 Aug. for the various grades of pepper sizes, classified as extra-large, large, medium, and culls. About $50 \%$ to $56 \%$ of the marketable yield consisted of medium size peppers (data not shown). About
$12 \%$ to $16 \%$ was extra large peppers and $32 \%$ to $35 \%$ consisted of large peppers. For all categories of sizes (except culls), the largest yield occurred for the $1 / \mathrm{d}$ treatment (Table 2). The smallest yield of the extra large and large categories occurred for the $2 / \mathrm{d}$ treatment followed by the 1 /week treatment. However, no statistical differences occurred between treatments. The smallest yield of the medium category occurred for the 1 /week treatment, which was statistically different from the $1 / \mathrm{d}$ treatment.

Processing tomato. Results from the first west side tomato crop showed a very strong trend of decreasing yields from west to east across the plots. Evaluation of the drip irrigation system showed similar behavior in the drip tape discharge rates. Thus, a second crop was grown the following year that did not show this behavior in both yield and tape discharge rates. For the first crop, applied water ranged between 16.9 inches $(42.9 \mathrm{~cm})$ and 17.2 inches $(43.7$ $\mathrm{cm})$. Applied water was about 16.7 inches $(42.4 \mathrm{~cm})$ for all treatments for the second crop.

The largest yield of the first crop occurred for the $1 / \mathrm{d}$ treatment, while the smallest yield occurred for the 1/ week treatment (Table 1). For the second crop, the largest and smallest yields occurred for the 2 /week and the $1 /$ week treatments, respectively. However, differences between treatment yields were not statistically significant for both crops.

The effect of irrigation frequency on tomato quality is summarized in Table 3. The largest red fruit percentage occurred for the $1 / \mathrm{d}$ treatment and the smallest for the $1 /$ week treatment in both crops. The $1 / \mathrm{d}$ treatment had the smallest green fruit fraction in both

Table 3. Effect of irrigation frequency on soluble solids, color, and percent of the total yield consisting of red, green, and nonmarketable tomatoes. The higher the soluble solids content and lower the color, the better the fruit quality. For a given tomato crop, there were no statistically significant differences between irrigation frequencies in the quality characteristics at a level of significance of $5 \%$.

\begin{tabular}{|c|c|c|c|c|c|}
\hline $\begin{array}{l}\text { Irrigation } \\
\text { frequency }\end{array}$ & $\begin{array}{c}\text { Soluble } \\
\text { solids } \\
(\%) \\
\end{array}$ & Color & $\begin{array}{c}\text { Red } \\
\text { tomatoes } \\
(\%) \\
\end{array}$ & $\begin{array}{c}\text { Green } \\
\text { tomatoes } \\
(\%) \\
\end{array}$ & $\begin{array}{c}\text { Nonmarketable } \\
\text { tomatoes } \\
(\%) \\
\end{array}$ \\
\hline \multicolumn{6}{|l|}{ First tomato crop } \\
\hline 2 irrigations / $\mathrm{d}$ & 5.0 & 22.8 & 61.6 & 15.2 & 8.7 \\
\hline 1 irrigation/d & 4.9 & 22.8 & 68.4 & 10.9 & 6.8 \\
\hline 2 irrigations/week & 4.9 & 22.5 & 63.3 & 16.6 & 6.6 \\
\hline 2 irrigations /d & 4.5 & 24.3 & 76.2 & 13.3 & 8.8 \\
\hline 1 irrigation/d & 4.5 & 23.2 & 78.9 & 10.1 & 8.6 \\
\hline 2 irrigations/week & 4.7 & 23.5 & 77.0 & 13.9 & 5.7 \\
\hline 1 irrigation/week & 4.5 & 23.5 & 74.1 & 18.1 & 8.2 \\
\hline
\end{tabular}



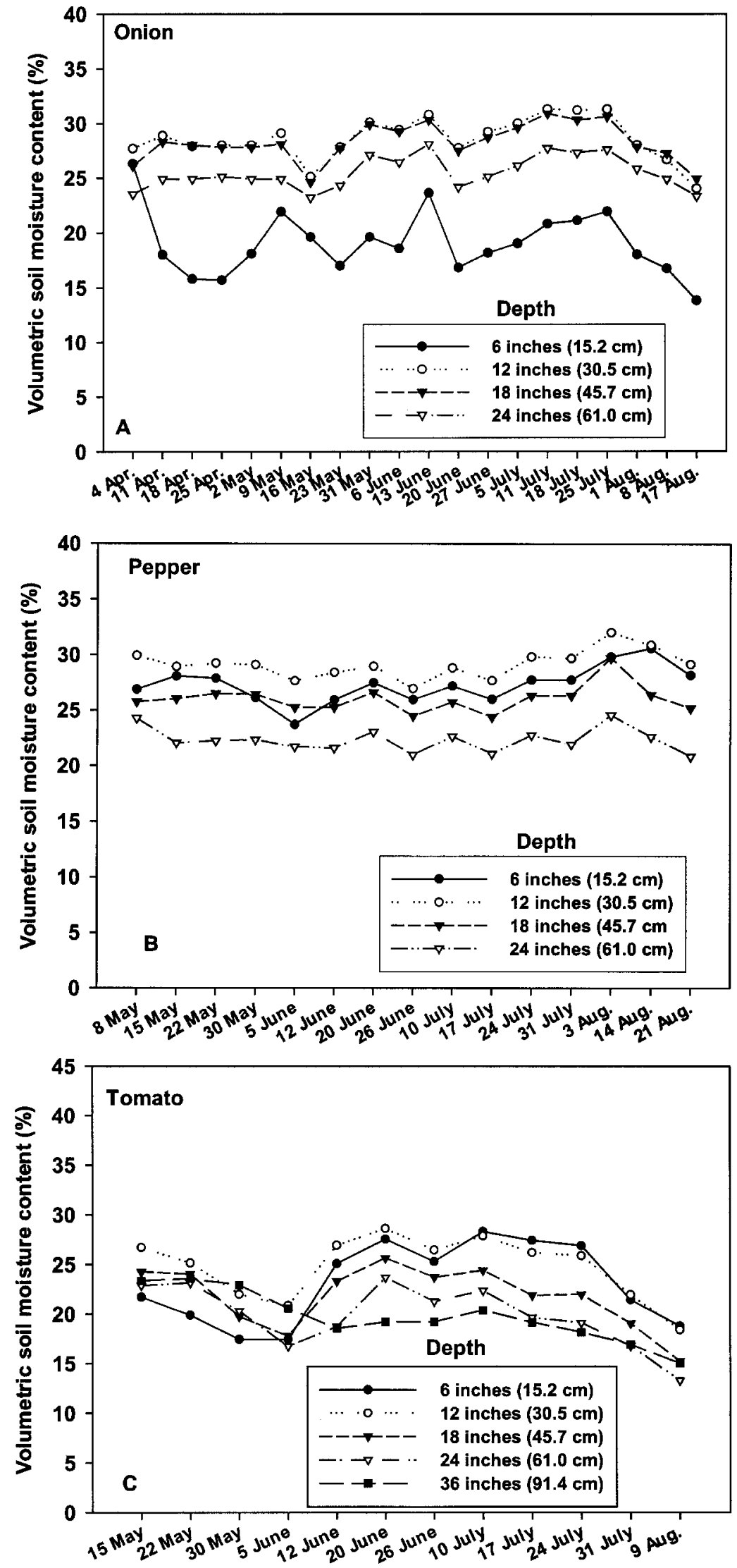

Fig. 1. Volumetric soil moisture content during the irrigation seasons for measurement depths of $6,12,18$, and 24 inches for the onion experiment $(A)$, the pepper experiment (B), and the second tomato crop (C) at the Westside Research and Extension Center, Five Points, Calif. Measurements were also made 36 inches $(91.4 \mathrm{~cm})$ deep for the tomato crop. years. The $2 / \mathrm{d}$ treatment had the largest percent nonmarketable fruit fraction in both years. Again, differences in these quality characteristics between treatments were statistically insignificant for both years.

Differences in soluble solids and color were statistically insignificant for both years. Soluble solids were slightly less for the second crop compared with the first crop. Color was slightly greater for the second crop, but not significantly different.

Results of the Davis trial (not shown) showed no statistical differences in red fruit yield for both irrigation frequency and installation depth treatments. Nointeraction occurred between depth and frequency treatments. Differences in solids and color between treatments were also insignificant.

SOIL MOISTURE CONTENT. Little or no seasonal trend was found in the soil moisture content of the daily-irrigated onion as shown in Fig. 1A. However, considerable variability occurred in the moisture content data at 6 inches deep, ranging from about $16 \%$ to $23 \%$ volumetric soil moisture content. Less variability occurred for the deeper depths. Average values for the 6, 12, 18, and 24inch depths were $19.0 \%, 28.6 \%, 28.3 \%$, and $25.5 \%$, respectively. The coefficients of variation were $10.3 \%$ for the 6 -inch depth and $5.2 \%$ to $5.6 \%$ for the deeper depths. Moisture content increased with depth to about 18 inches deep.

Little or no trend in soil moisture content with time was found for pepper as shown in Fig. 1B. Less soil moisture variability occurred with time for the peppers compared to onions. Moisture content at 6 inches was much more variable compared with the deeper depths. Average values of soil moisture content for the respective depths were $27.3 \%, 29.1 \%, 26.0 \%$, and $22.3 \%$. Coefficients of variation were $6.1 \%$ for the 6 inch depth and 4.4 to $4.9 \%$ for the deeper depths. Moisture content tended to decrease with depth.

Soil moisture measurements made during the second west side tomato crop showed soil moisture content to decrease with time during the initial growth stage, but then increase with time during the rapid growth stage until the time of cutback after 24 July (before harvest) as shown in Fig. 1C. The average seasonal volumetric soil moisture contents were $23.1 \%, 24.8 \%, 21.8 \%$, and $19.8 \%$ for the respective depths of 6 , 12,18 , and 24 inches. Coefficients of 


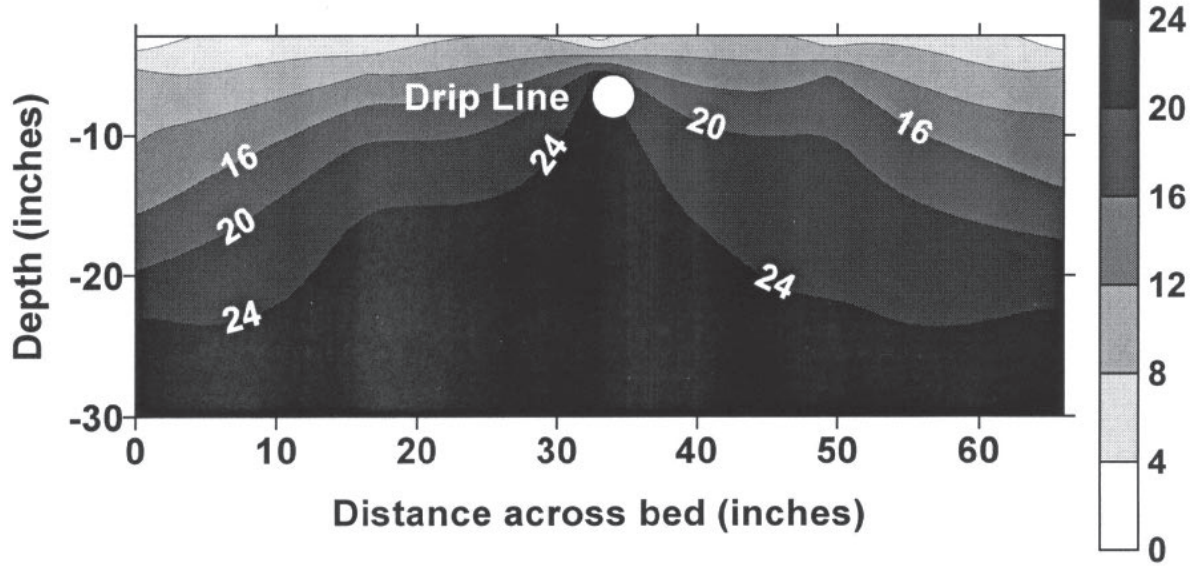

Fig. 2. Pattern of volumetric soil moisture content (\%) around the drip line for one irrigation per day of onion. The pattern consists of lines or contours of equal soil moisture content developed with a graphics contouring software. Depth of the drip line was 8 to 9 inches $(20.3 \mathrm{~cm}$ to $22.9 \mathrm{~cm})$. Bed spacing was 40 inches $(101.6 \mathrm{~cm}) .1$ inch $=2.5 \mathrm{~cm}$.

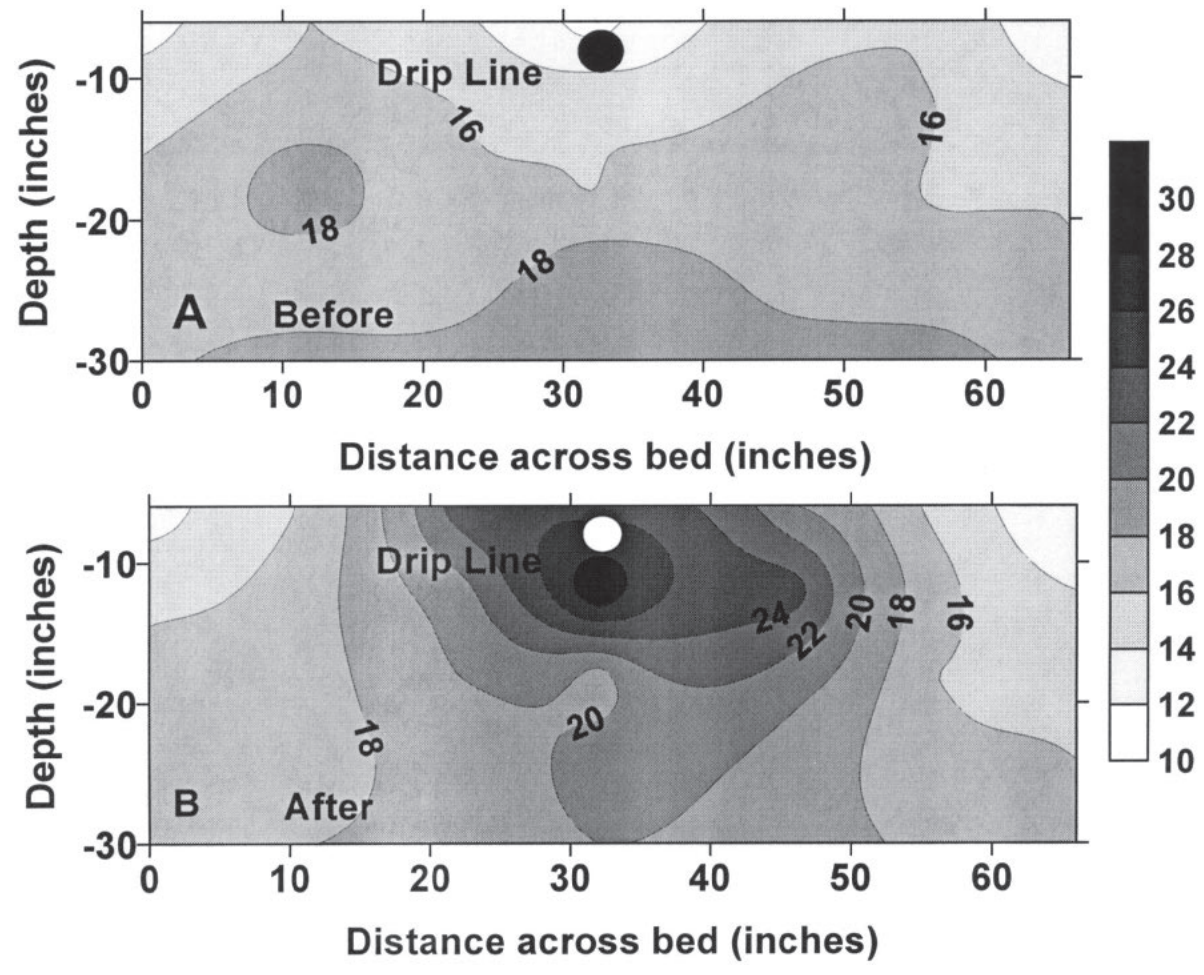

Fig. 3. Patterns of volumetric soil moisture content (\%) around the drip line for one irrigation per week of the first tomato crop at the Westside Research and Extension Center, Five Points, Calif. Patterns were determined just before an irrigation and just after an irrigation. The figures consist of lines or contours of equal soil moisture content developed with a graphics contouring software. Depth of the drip line was 8 to 9 inches $(20.3 \mathrm{~cm}$ to $22.9 \mathrm{~cm})$. Bed spacing was 66 inches $(167.6 \mathrm{~cm}) .1$ inch $=2.5 \mathrm{~cm}$.

variation were $17.8 \%, 12.8 \%, 14.5 \%$, and $15.8 \%$ for the respective depths.

Wetting patterns. The effect of daily drip irrigation on wetted pattern around the drip line was illustrated by data from onion irrigations as shown in Fig. 2. Above the drip line, soil moisture
The effect of weekly drip irrigation on wetting pattern is illustrated using data just before an irrigation and just after on irrigation for processing tomato as shown in Fig. 3A and B. Considerable drying in the vicinity of the drip line occurred just before an irrigation. After the irrigation, volumetric soil moisture content increased considerably, from about $12 \%$ to $14 \%$ to about $26 \%$ to $28 \%$ in the vicinity of the drip line. Directly below the drip line, soil moisture content decreased with increasing depth. Lateral wetting appeared to be about 16 inches $(40.6 \mathrm{~cm})$ on either side of the drip line.

It should be noted that different soil types occurred for the onion and tomato experiments. However, in spite of soil differences, these patterns illustrate the relative differences that can occur due to irrigation frequency. The wetting pattern similar to that of the 1 / $\mathrm{d}$ onion irrigation frequency was found in a clay loam soil for daily irrigations (Hanson et al., 1997).

\section{Conclusions}

These results indicate that for relatively shallow rooted crops, an irrigation frequency of two irrigations per week should be used. Frequencies of one per week should be avoided on sandy soil. Yields of the 1 /week treatment were statistically different from those of the $1 / d$ treatment for onion and pepper. The fall lettuce crop also showed a much smaller yield compared to the other frequencies, although yield differences of this crop were not statistically significant, possibly due to the smaller sample size. For deeper-rooted crops, irrigation frequency had little effect on crop yield on silt loam. Yield differences of the tomato crops generally were not statistically significant, except for the first west side tomato crop which showed significant differences between the $2 / \mathrm{d}$ and $1 / d$ treatments. Fruit quality in general was not affected by irrigation frequency except for medium peppers, for which significant differences occurred between the $1 / \mathrm{d}$ and $1 /$ week treatments.

From a practical viewpoint, we recommend an irrigation frequency of about 2 /week for the shallow-rooted vegetable crops (lettuce, onion, and pepper) for the soils used in these experiments and for climatic conditions similar to that of the Central Valley. There appears to be no merit for irrigating at a higher frequency, particularly 
multiple times per day. For the deeprooted tomato crops, perhaps a l/week irrigation is sufficient in these soil types; however, we still recommend a 2 /week frequency as a margin of safety. It should be noted that different results might occur for the shallow rooted crops in finer-textured soil and a climate with smaller evapotranspiration rates. Under these conditions, a frequency of $\mathrm{l} /$ week may be adequate for shallowrooted crops.

\section{Literature cited}

Bucks, D.A., L.J. Erie, and O.R. French. 1974. Quantity and frequency of trickle and furrow irrigation for efficient cabbage production. Agron. J. 66(1):53-57.

Bucks, D.A., L.J. Erie, O.F. French, F.S. Nakayama, and W.D. Pew. 1980. Subsurface trickle irrigation management with multiple cropping. Trans. Amer. Soc. Agr. Eng. 24(2):14821489.

Caldwell, D.S.,W.E. Spurgeon, and H.L. Manges. 1994. Frequency of irrigation for subsurface dripirrigated corn. Trans. Amer. Soc. Agr. Eng. 37(4):1099-1103.

El-Gindy, A.M. and A.M. El-Araby. 1996. Vegetable crop response to surface and subsurface drip under calcareous soil, p. 1021-1028. In: C. R. Camp, E. J. Sadler, and R. E. Yoder (eds.). Proc. Intl. Conf. Evapotranspiration and Irrigation Scheduling. Amer. Soc. Agr. Eng., St. Joseph, Mich.

Ellis, I.E., E.G. Kruse, A.E. McSay, C.M.U. Neale, and R.A. Horn. 1986. A comparison of five irrigation methods on onion. HortScience 21(16):1349-1351.

Freeman, I., J. Blackwell, and K.V. Garzoli. 1976. Irrigation frequency and total water applications with trickle and furrow systems. Agr. Water Mgt. 1:21-31.

Grattan, S.R., W. Bowers, A. Dong, R.L. Synder, J. Carroll, and W. George. 1998. New crop coefficients estimate water use of vegetables, row crops. Calif. Agr. 52(1):16-21.

Hanson, B.R., D.M. May, and W.E. Bendixen. 1997. Wetting patterns under surface and subsurface drip irrigation. Amer. Soc. Agr. Eng. Paper 272178.

Hartz, T.K. 1993. Drip-irrigation scheduling for fresh-market tomato production. HortScience 28(1):35-37.

Hutmacher, R.B., S.S. Vail, J.G. Muthamia, V. Mwaja, and R.C. Liu. 1985. Effect of trickle irrigation frequency and installation depth on tomato growth and water status, p. 798-804. In: Drip/Trickle Irrigation in Action, Proc. 3rd Intl. Drip/Trickle Irrigation Congr.

Sammis, T.W. 1980. Comparison of sprinkler, trickle, subsurface, and furrow irrigation methods for row crops. Agron. J. 72(5):701-704. 